\title{
Content Curatorship and Collaborative Filtering: A Symbolic Interactionist Approach
}

\author{
Kerry Chipp, Carola Strandberg, Atanu Nath, and Meyser Abduljabber
}

\begin{abstract}
This paper explores the premise whether sophisticated algorithms that drive curatorship of content for consumers consider a symbolic interactionist perspective on consumer desire for content and whether content offerings, personalisation and the consequent shaping of curatorship algorithms can be based on such an understanding. Curatorship of online content, whether this be product or information based, drives value, consumer engagement and profitability. Curatorship and recommender systems also deliver a personalised experience of the product or services. A review of the reasoning behind such systems reveals that most follow an empirical perspective, namely, the use of statistical tools and information systems algorithms on a behavioural dataset. A theoretically driven approach appears to be lacking. This paper seeks a theoretical approach to online content curatorship embedded in symbolic interactionism. In addition, it seeks to tease out the approach to one that embraces both notions of content curation based on similarity but also on a desire for difference and change. The paper looks at symbolic interactionism in the context of social and individual selves, its role in collaborative filtering, advances a set of propositions for a curation and collaborative filtering model and ends with the possible implications for marketing.
\end{abstract}

Keywords Symbolic interactionism • Content curation • Collaborative filtering • Online curation

\author{
K. Chipp \\ University of Pretoria, Pretoria, South Africa \\ Royal Institute of Technology (KTH), Stockholm, Sweden \\ e-mail: chippk@gibs.co.za \\ C. Strandberg \\ Luleå University of Technology, Luleå, Sweden \\ e-mail: carola.strandberg@1tu.se
}

\author{
A. Nath $(\triangle)$ \\ Western Norway University of Applied Sciences, Sogndal, Norway \\ e-mail: atanu.k.nath@hvl.no \\ M. Abduljabber \\ Royal Institute of Technology (KTH), Stockholm, Sweden \\ e-mail: meyser@kth.se
}




\section{Introduction}

Do sophisticated algorithms that drive curatorship of content for consumers from organisations such as Netflix consider a theoretical perspective on consumer desire for that same content? Blumer (1969) emphasises that humans interact with things (material objects, institutions or people) based on the meaning these have for them. Meaning is constructed in a social context. Can we understand content offerings, personalisation and the consequent shaping of curatorship algorithms based on such an understanding? With the increasingly interactive nature of the Internet with Web 2.0, the role and influence of the social group become heightened.

No one doubts that the amount of content available online is staggering. It has become apparent that the curatorship of such content, whether this be product or information based, drives value, consumer engagement and profitability. Curatorship is also aimed at delivering a personalised experience of the product or service (Lu, Wu, Mao, Wang, \& Zhang, 2015). Recommender systems have largely been developed in response and function from analysing user behaviour along with that of other users ( $\mathrm{Lu}$ et al., 2015). A review of the reasoning behind such systems reveals that most follow an empirical perspective, namely, the use of statistical tools and information systems algorithms on a behavioural dataset. A theoretically driven approach appears to be lacking. Such an approach would demand the design of recommender systems be based on a deeper understanding of consumer choice rather than their demographics, their behaviour and their similarity to others.

This paper seeks to make the following two contributions: first is to establish the potential for a theoretical approach to online content curatorship, one that is embedded in symbolic interactionism. The second contribution is to tease out this approach to one that embraces both notions of content curation based on similarity but also on a desire for difference and change. In the following sections, we shall briefly discuss our understanding of symbolic interactionism in the context of social and individual selves, its role in collaborative filtering, and advance a set of propositions for a curation and collaborative filtering model. The paper ends with the possible implications for marketing.

\section{Symbolic Interactionism and the Social Self}

The term symbolic interactionism (SI) was first coined by Herbert Blumer in 1937 based on the work of George Herbert Mead, in reference to a distinctive approach to the study of human conduct and group life (Blumer, 1969). SI rests on three principles: first, the premise that humans act towards things on the basis of the meaning these things have to them. These things or objects can be physical, social or abstract, 
such as other human beings, material objects, institutions, guiding ideals, selfconcepts, activities or situations. Second, the meaning assigned to these things stems from the social interaction that the individual has with others, and third, these meanings are handled and transformed in an interpretative process that we as humans use in order to make sense of and deal with the things we encounter in the world.

Many are the authors beyond Mead and Blumer who have contributed to SI: John Dewey, William James, Charles Horton Cooley, W.I. Thomas, Robert E. Park, Florian Znaniecki, James Mark Baldwin, Robert Redfield, Everett Hughes and Louis Wirth to name a few (Blumer, 1969; Fine, 1993). SI and the three cornerstones depicted by Blumer have received wide recognition and acceptance, been used both in textbooks and applied in different fields of research, but have not been without criticism, contradiction or question (see Hall, 1972; Huber, 1973; McPhail and Rexroat, 1979; Stryker, 1988). The voiced criticism in turn has been countered and sometimes discredited as misguided by other scholars (e.g. Maines, 1977, 1988). Snow (2001) considers Blumer's three pillars being too tightly linked to the issue of meaning and interpretation and instead proposes highlighting four orienting interactionist principles as the basis of SI: the principle of interactive determination, the principle of symbolisation, the principle of emergence and the principle of human agency. These principles encompass Blumer's conceptualisation and are according to the author implied but not articulated in the work by Blumer (Snow, 2001).

Core to SI is the meaning of things and how this drives behavioural action. Blumer (1969) separated this approach from psychology and sociology as it focused on an outcome rather than causal factors, such as stimuli, attitudes, motives and perception, or to social constructs such as status demand, social roles, culture, norms and values.

Traditionally, the source of meaning has been attributed either to being intrinsic, as a natural part of the object itself, visible through observation, with no process of formation, or as being attributed as an expression of an individual's psyche. In the latter regard, meaning is given to the thing by the individual for whom the thing has meaning, as an expression of the sensations, feelings, ideas, memories, motives and attitudes set in motion in connection with the perception of the thing. In SI meaning is seen as a social product, instilled through a process of interaction between people, based on how other people act towards the person with regard to the thing. The meaning of the thing is thus derived from the actions of and interactions with others (Blumer, 1969). The self is fundamentally a social self, and it is responsive based on its links with others.

The notion of a social self is fundamental to Web 2.0. Cova, a long proponent of brand communities and tribal marketing, has demonstrated that the interactive nature of Web 2.0 has unleashed the power of the social group (Cova \& White, 2010). In their 2010 paper, Cova and White emphasise the role of meaning which is generated by both companies and active consumers. They speak of a "linking value" which attaches brands to their consumers. Such a link is generated by communal relationships to create feelings of well-being and passion, feelings which they then share with others. More pointedly, linking value provides cultural value as 
consumers selected ideas, symbols, codes, texts and the like which are then projected onto products and services (Cova \& White, 2010). The core of this approach is twofold: one, the active consumer community participation, which relates to the SI principle of human agency, and two, the SI generation of meaning, which speaks to the principles of interactive determination symbolisation and emergence.

According to Mead (1934) symbolic interaction focuses on rationality and the interpreted meaning of indications such as gestures, common symbols, language, remarks and actions as basis for human actions. The SI generation of meaning is assigned and used through a two-step process of interpretation where the individual actor firstly has to communicate with itself to identify and indicate the things towards which it is acting that have meaning (Blumer, 1969). Secondly, throughout this self-interaction process, the individual needs to interpret, establish and handle these meanings by selecting, checking, connecting, regrouping and transforming meanings with regard to the situation at hand. Therefore, in SI, the use of meaning is not a static, automatic response to established meanings but rather a formative process where meanings are used and modified as instruments in guiding and forming actions. Meaning is thus a vital element in understanding human behaviour, interactions and social processes (Blumer, 1969). It would appear, therefore, that Web 2.0 is ideally suited to SI.

The question then arises if SI can contribute to how content is selected and presented to individuals online. Since society consists of individuals interacting with each other, social interaction is vital in its own right as it is a process where the actions of others enter as positive factors in forming our own conduct (Mead, 1934). The online environment presents an interaction opportunity at unprecedented levels. Nevertheless, Mead emphasises that as humans we possess a "self" meaning that we can be an object of our own action, defining ourselves, and that we act towards ourselves based on the kind of object we are in our own eyes. However, like other objects, the meaning of the self-object is also interpreted and formed through the social interaction process, where we see ourselves based on how others see us.

Through a process of role-taking, the individual sees and evaluates itself from the perspective of three types of roles: that of discrete individuals, that of discrete organised groups and that of the abstract community. This process is referred to by Mead as the "generalised other". Based on this self-interaction, we give ourselves meaning, make indications to ourselves and direct our actions whether it is feeling, doing, thinking, intending or saying something. Human life thus consists of a continuum of situations calling for action, and these actions are based on what we perceive, how we interpret and assess what we perceive in the situation we are in and the course of action we envision in this situation. It is this social process in society that creates and upholds the rules of a culture (Mead, 1934). In content curatorship, content which is presented based on social similarity will therefore communicate a certain self-image to consumers, an image which currently rests on notions of similarity and shared group meaning rather than conflict or difference. 


\section{Symbolic Interactionism and the Individual Self}

As our societies become more networked, we are faced with choices from among abundance, rather than scarcity, of information. We need curation to make sense out of this overabundance of information and choice. Two dimensions emerge, one is productive curation, based upon content produced and intended for sharing within networks; the other being consumption curation, content that is intended to be consumed (Davis, 2016).

In case of productive curation, the work of self-presentation involves complex decisions about documentation, sharing, privacy and publicity. However, in case of consumption curation, or curation of content from their networks (social or commercial, such as an online shopping site), the constraints may be far less; rather efficiency and efficacy take the centre stage. People present different versions of selves across time and different networks in productive curation. The compulsion to do so in consumption curation is not as much driven by the need for self-presentation; however, this depends on the type of content consumed (Hogan, 2010). This may well hold true for media consumption. Other forms of consumption, for example, shopping for clothes online, have image formation as the end product; hence, it is conceivable that similar to productive curation, self-presentation plays a role in this form of consumption. Thus, self-presentation is relevant in both dimensions, albeit to a lesser degree in consumptive than productive curation where self-presentation is a performance intended for self as well as others explicitly (Davis \& Jurgenson, 2014).

\section{Symbolic Interactionism and Consumer Behaviour}

Solomon (1983) makes the case that the consumption of many products contributes to the consumer's composition of the social environment such as the social reality, the self-concept and behaviour. The social meanings latent in products serve as a guide to social roles (Solomon, 1983). Leigh and Gabel (1992) discuss the effect of SI on consumer behaviour and its effects on marketing strategy: first, the formulation of personal self-concept and, second, the role of reference groups who inform symbolic purchasing behaviour and thus drive consumer perceptions of market segment membership. Such reference groups form perceptions of exclusivity, which may drive consumption behaviour, particularly in times of transition, known as liminal periods. Leigh and Gabel (1992) thus allude to the avoidance, disclaimant, aspirational and contactual reference groups in consumer behaviour (Arnould, Price \& Zinkhan, 2002).

The more socially consumed the product is, the greater the social influence. An illustrative study was conducted by Piacentini and Mailer (2004) on teenage clothing; teenagers are in a time of transition or a liminal period, and clothing is a social tool. Thus, the clothes they had chosen figure both as a way of self-expression and as a way of judging the environment (Piacentini \& Mailer, 2004). Times of liminality 
have also been found to be a minefield of self-deconstruction and reconstruction through possessions and services (see Noble \& Walker, 1997). Thus, the social self and its construction have been greatly aided in consumer behaviour through forms of SI. Moreover, it is evident that there are both non-membership and membership groups to which individuals wish to associate and disassociate. Hence they may aspire to products, services and information content of groups they are not currently a member and reject products, services and information from groups they wish to disassociate even though they could be members thereof. This process is sometimes enhanced during periods of personal change or luminal periods. Thus, there is a case for content selected on similarity as well as content selected on difference.

\section{Recommender Systems}

The plethora of online content, products and options has had to be made more navigable for consumers who are awash in a sea of choice. Recommender systems are commonly used to reduce the information overload consumers experience in many sites (Bobadilla, Ortega, \& Hernando, 2012). Most recommendation systems use a filtration process to personalise content or product choice in four ways; first, there is content-based filtering based on the content user past choices, such as films of a particular genre if that genre has been chosen before. Second, there is demographic filtering which rests on the premise that demographic commonalities (such as similar age groups) will mean content preference similarity too (Bobadilla et al., 2012). The third approach is termed collaborative filtering (CF) which operates of user ratings of items. Other users are then offered a set of options based on the ratings of users who are similar to them (Barragáns-Martínez, Costa-Montenegro, Burguillo, Rey-López, Mikic-Fonte, \& Peleteiro, 2010; Bobadilla et al., 2012). The fourth approach is a combination of $\mathrm{CF}$ with one of the first two (content or demographic filtering).

The assumption behind such systems is that of similarity. Too much choice is viewed as negative, and individuals are perceived to appreciate the personalisation engendered by the curatorship. Nevertheless, not all research on choice has found that this is negative for individuals (Scheibehenne, Greifeneder, \& Todd, 2010). Furthermore, choice has been viewed as integral to self-expression, need for uniqueness and individual variety-seeking behaviour (Berger \& Heath, 2007; Kim \& Drolet, 2003). When it comes to content curation, in non-electronic settings, research has found that difference is a tool to signal identity, particularly in domains which are often used as identity signals, such as music (Berger \& Heath, 2007). Individuals often want to strongly disassociate themselves with the mass in such situations (Berger \& Heath, 2007). Indeed brands and individuals are perceived socially as "cool" when expressing autonomy from social groups and social norms (Warren \& Campbell, 2014).

There is a balance between sameness and difference in the individual construction of the social self. Blumer's (1969) second principle is based on the assignment of meaning through social interaction; hence the influence of the others is always present, and thus self-expression is a mix of demonstrating individualism as well as 
group membership. Snow (2001) emphasised human agency in SI; thus, the individual always plays the leading role in meaning construction and choice. Therefore it is not optimal to have content selection systems based on similarity or difference alone; there needs to be a balance, and human agency needs to be embraced.

Over time the group has been found to be integral to both the quest for difference and for sameness, whether this be for distinction (Ariely \& Levav, 2000) or similarity (Venkatesan, 1966). Papyrina (2012) found evidence in support of this depending on prior interaction with the group and group awareness of individual decisions.

The translation of distinction, variety seeking or autonomy into recommender systems appear to be largely absent from current formulations of such systems in general and collaborative filtering in particular, which will be demonstrated below.

\section{Current State of Work on Collaborative Filtering}

\section{Intelligent Algorithms, Statistical Modelling and Base Assumption Testing}

$\mathrm{CF}$ is viewed as the most interesting and open research field at present (Bobadilla et al., 2012; Ortega, Hernando, Bobadilla, \& Kang, 2016; Ortega, Sánchez, Bobadilla, \& Gutiérrez, 2013). There are two main approaches to how collaborative filtering is done online. The first is based on behavioural models and functions of learning algorithms which make use of different statistical assumptions. The bulk of these studies appear in Information Systems journals and focus on the mechanics and possibilities of intelligent software (e.g. Barragáns-Martínez et al., 2010; Bobadilla, Ortega, \& Hernando, 2012; Cheng, Yin, Dong, Dong, \& Zhang, 2016; Liao \& Lee, 2016; Nilashi, Jannach, Ibrahim, \& Ithnin, 2015). Users are aggregated or clustered by their shared ratings of similar items, and various means of optimal aggregation are debated and tested (Bobadilla et al., 2012; Jeong, Lee \& Cho, 2010; Lee, Lee, Lee, Hwang \& Kim, 2016; Ortega et al., 2013, 2016; Xin, Ouuyang \& Zhang, 2011). Tests have looked at the use of Pareto dominance (Ortega et al., 2013), clustering algorithms (Liao \& Lee, 2016; Nilashi et al., 2015), semanticbased interest sequences (Cheng et al., 2016) and the recency and update of material (Jeong et al., 2010), to name but a few.

\section{Network, User or Context Sensitive CF}

The second approach starts to move beyond simple user similarity calculations. There is a realisation that user behaviour is contextual, and users can influence each other (Koren, 2010). Some are built on the notion of a social network of individuals who can 
interact and influence each other (Barragáns-Martínez et al., 2010). Multipronged strategies have been advocated, where user-based, item-based and statistically based algorithms are combined (e.g. Lee et al., 2016)

Common to all these approaches is the notion of user similarity and collaboration with others who are alike (Kim, Ha, Lee, Jo, \& El-Saddik, 2011). Indeed none of the literature actively seeks otherness or offering users content which could be seen as different to what they would rate (rating-based systems) or others like them (those who rate similar things in similar ways). Thus, it would appear that the central premise of recommendation systems in general and CF systems in particular is that of similarly.

\section{Collaborative Filtering and the Social Self}

More recently and outside the algorithmic and IT-based approaches to CF is some recognition of recommendation agents as forming part of a sociological system (Fotopoulou \& Couldry, 2015; Lazer, 2015). The role of the network of people has been found to be more important in the filtering of content (Li, Hsiao, \& Lee, 2013) rather than the content itself. In relation to this, Lazer (2015) focused on the impact of social bias that occurred when groups of like individuals clustered together and only viewed content that they mutually liked rather than content they did not mutually share. This is similar to the research by Hollander (2008) which found that social networks serve to make groups of individuals more insular and polarised. Neither of these authors truly considered the role of recommendation systems and collaborative filtering, based on heightened similarity indices, could accelerate or even initiate this process.

Fotopoulou and Couldry (2015), operating from a media and communications point of view, approached "the development of a digital infrastructure as a sociotechnical process" (p. 236). Their approach is far more sociological as their perspective asserts that the technological infrastructure is intertwined with social and cultural expectations of life with digital technologies.

Their study viewed content curation through a process termed "community tagging" based on geographic place. Once an individual identified with the community, in this case shared geography, they were exposed to content relevant to the locale. Consequently they embraced one point of interest, a shared physical space, to share other content. The tagging system itself was user generated, making the content more engaging and removing it from the domain of algorithms. Such a system has echoes of the "linking value" of Cova and White (2010). Therefore, unlike most recommender systems and collaborative filters, one point of self-identified important contact could be sufficient for a content offering rather than a statistically or algorithmically deduced $k$ means contacts across a set of data. Our alternative approach ascribes far more agency to the consumer; they can actively 
select groups to whose choices they can be exposed and to whom their own personal choices can be represented. Thus, the consumer would actively signal membership and associative groups and have content curated on a potential basis of both difference and similarity.

\section{Propositions for Curation and Collaborative Filtering Model}

Based on the discussion above, we come to three propositions towards a content curation and collaborative filtering model and to recommend future research in this area.

Proposition 1 Conventional recommender systems enhance selection choices for situations where consumers wish to act with others, and thus consumers will display greater engagement with the selection on offer.

Proposition 2 Need for uniqueness/variety/distinction would be serviced through a self-selected single point of similarity to an aspirational group.

Proposition 3 The ability to choose between self and social influence will optimise situational selection for consumers, and they will display greater engagement with the selection on offer.

\section{Implications for Marketing}

Marketers already see the use and benefits of curating content for their customers, whether this be product or information based, since it drives value, consumer engagement and profitability. It is clear that curating and tailoring content are vital in providing an optimal consumer experience. But what type of curation is best suited for certain individuals and certain situations? As Leigh and Gabel (1992) put it: marketers' goal should be to create and visualise their products' and services' image and symbol through a well-strategised marketing programme to those consumers that would find the content most relevant to themselves. By matching consumer preferences and objectives for content curation and the curation features available/offered, marketers can increase the perceived usefulness of the curation tool, offer a better consumer experience and achieve a higher engagement with the selection on offer. Knowing what drives the consumer in this case unlocks the secrets to how to present them with the most appropriately curated content all the while providing them with more control over choices. 


\section{Conclusion}

$\mathrm{CF}$ has been dominated by technical papers seeking to heighten the similarity between consumers. The field has viewed individuals as part of a social network but only to the extent that correspondence between them can be converted into content offerings. Thus, these technologies could be actively decreasing the range of content to which one person can be exposed. Not surprisingly, there has been disquiet that social networks make individuals more polarised and insular as they are only exposed to things and people that they are already alike.

A more sociological perspective has moved away from the top-down, marketerdriven models, sought one point of similarity (rather than the maximum points of similarity) and opened fora for users to tag content themselves based on a single point of similarity, so they can be exposed to distinctive and varied content.

\section{References}

Ariely, D., \& Levav, J. (2000). Sequential choice in group settings: Taking the road less traveled and less enjoyed. Journal of Consumer Research, 27(3), 279-290.

Arnould, E. J., Price, L., \& Zinkhan, G. M. (2002). Consumers. New York: McGraw-Hill/Irwin.

Barragáns-Martínez, A. B., Costa-Montenegro, E., Burguillo, J. C., Rey-López, M., MikicFonte, F. A., \& Peleteiro, A. (2010). A hybrid content-based and item-based collaborative filtering approach to recommend TV programs enhanced with singular value decomposition. Information Sciences, 180(22), 4290-4311.

Berger, J., \& Heath, C. (2007). Where consumers diverge from others: Identity signaling and product domains. Journal of Consumer Research, 34(2), 121-134.

Blumer, H. (1969). Symbolic interactionism perspective and method. New Jersey: Prentice Hall Upper Saddle River.

Bobadilla, J., Ortega, F., \& Hernando, A. (2012). A collaborative filtering similarity measure based on singularities. Information Processing \& Management, 48(2), 204-217.

Cheng, W., Yin, G., Dong, Y., Dong, H., \& Zhang, W. (2016). Collaborative filtering recommendation on users' interest sequences. PloS One, 11(5), 1-17.

Cova, B., \& White, T. (2010). Counter-brand and alter-brand communities: The impact of web 2.0 on tribal marketing approaches. Journal of Marketing Management, 26(3-4), 256-270.

Davis, J. L. (2016). Curation: A theoretical treatment. Information, Communication \& Society, 4462(August), 1-14.

Davis, J. L., \& Jurgenson, N. (2014). Context collapse: Theorizing context collusions and collisions. Information, Communication \& Society, 17(4), 1-10.

Fine, G. A. (1993). The sad demise, mysterious disappearance, and glorious triumph of symbolic interactionism. Annual Review of Sociology, 19(1), 61-87.

Fotopoulou, A., \& Couldry, N. (2015). Telling the story of the stories: Online content curation and digital engagement. Information, Communication \& Society, 18(2), 235-249.

Hall, P. M. (1972). A symbolic interactionist analysis of politics. Sociological Inquiry, 42, 35-75.

Hogan, B. (2010). The presentation of self in the age of social media: Distinguishing performances and exhibitions online. Bulletin of Science, Technology \& Society, 30(6), 377-386.

Hollander, B. A. (2008). Tuning out or tuning elsewhere? Partisanship, polarization, and media migration from 1998 to 2006. Journalism \& Mass Communication Quarterly, 85(1), 23-40.

Huber, J. (1973). Symbolic interaction as a pragmatic perspective: The bias of emergent theory. American Sociological Review, 38, 278-284. 
Jeong, B., Lee, J., \& Cho, H. (2010). Improving memory-based collaborative filtering via similarity updating and prediction modulation. Information Sciences, 180(5), 602-612.

Kim, H. S., \& Drolet, A. (2003). Choice and self-expression: A cultural analysis of variety-seeking. Journal of Personality and Social Psychology, 85(2), 373-382.

Kim, H.-N., Ha, I., Lee, K.-S., Jo, G.-S., \& El-Saddik, A. (2011). Collaborative user modeling for enhanced content filtering in recommender systems. Decision Support Systems, 51(4), 772-781.

Koren, Y. (2010). Collaborative filtering with temporal dynamics. Communications of the ACM, $53(4), 87-89$.

Lazer, D. (2015). The rise of the social algorithm. Science, 348(6239), 1090.

Lee, J., Lee, D., Lee, Y.-C., Hwang, W.-S., \& Kim, S.-W. (2016). Improving the accuracy of top-N recommendation using a preference model. Information Sciences, 348, 290-304.

Leigh, J. H., \& Gabel, T. G. (1992). Symbolic interactionism: Its effects on consumer behaviour and implications for marketing strategy. Journal of Services Marketing, 6(3), 5-16.

Li, Y.-M., Hsiao, H.-W., \& Lee, Y.-L. (2013). Recommending social network applications via social filtering mechanisms. Information Sciences, 239, 18-30.

Liao, C.-L., \& Lee, S.-J. (2016). A clustering based approach to improving the efficiency of collaborative filtering recommendation. Electronic Commerce Research \& Applications, 18, 1-9.

Lu, J., Wu, D., Mao, M., Wang, W., \& Zhang, G. (2015). Recommender system application developments: A survey. Decision Support Systems, 74, 12-32.

Maines, D. R. (1977). Social organization and social structure in symbolic interactionist thought. Annual Review of Sociology, 3, 235-259.

Maines, D. R. (1988). Myth, text, and interaction complicity in the neglect of Blumer's macrosociology. Symbolic Interaction, 11(1), 43-57.

McPhail, C., \& Rexroat, C. (1979). Mead vs. Blumer: The divergent methodological perspectives of social behaviorism and symbolic interactionism. American Sociological Review, 44(3), 449-467.

Mead, G. H. (1934). Mind, self and society (Vol. 111). Chicago: University of Chicago Press.

Nilashi, M., Jannach, D., bin Ibrahim, O., \& Ithnin, N. (2015). Clustering- and regression-based multicriteria collaborative filtering with incremental updates. Information Sciences, 293, 235-250.

Noble, C. H., \& Walker, B. A. (1997). Exploring the relationships among liminal transitions, symbolic consumption, and the extended self. Psychology \& Marketing, 14(1), $29-47$.

Ortega, F., Hernando, A., Bobadilla, J., \& Kang, J. H. (2016). Recommending items to group of users using matrix factorization based collaborative filtering. Information Sciences, 345, 313-324.

Ortega, F., Sánchez, J.-L., Bobadilla, J., \& Gutiérrez, A. (2013). Improving collaborative filteringbased recommender systems results using Pareto dominance. Information Sciences, 239, 50-61.

Papyrina, V. (2012). If I want you to like me, should I be like you or unlike you? The effect of prior positive interaction with the group on conformity and distinctiveness in consumer decision making. Journal of Consumer Behaviour, 11(6), 467-476.

Piacentini, M., \& Mailer, G. (2004). Symbolic consumption in teenagers' clothing choices. Journal of Consumer Behaviour, 3(3), 251-262.

Scheibehenne, B., Greifeneder, R., \& Todd, P. M. (2010). Can there ever be too many options? A meta-analytic review of choice overload. Journal of Consumer Research, 37(3), 409-425.

Snow, D. A. (2001). Extending and broadening Blumer's conceptualization of symbolic interactionism. Symbolic Interaction, 24(3), 367-377.

Solomon, M. R. (1983). The role of products as social stimuli: A symbolic interactionism perspective. Journal of Consumer Research, 10(3), 319-329.

Stryker, S. (1988). Substance and style: An appraisal of the sociological legacy of Herbert Blumer. Symbolic Interaction, 11(1), 33-42.

Venkatesan, M. (1966). Experimental study of consumer behavior conformity and independence. Journal of Marketing Research (JMR), 3(4), 384-387.

Warren, C., \& Campbell, M. C. (2014). What makes things cool? How autonomy influences perceived coolness. Journal of Consumer Research, 41(August), 543-563.

Xin, L. U. O., Ouuyang, Y., \& Zhang, X. (2011). Improving latent factor model based collaborative filtering via integrated folksonomy factors. International Journal of Uncertainty, Fuzziness \& Knowledge-Based Systems, 19(2), 307-327. 